\title{
Postabortion Contraceptive Acceptance Rate and Its Determinants among Women Receiving Abortion Service before Discharge from the Health Facilities in Harar, Eastern Ethiopia
}

\author{
Endalkachew Atnafu, ${ }^{1}$ Biftu Geda, ${ }^{2}$ Lemessa Oljira, ${ }^{3}$ Genanaw Atnafe, ${ }^{4}$ Dawit Tamiru, ${ }^{4}$ \\ Abdi Birhanu $\left(\mathbb{0},{ }^{5}\right.$ Getahun Tiruye, ${ }^{4}$ Haregeweyn Kibret, ${ }^{4}$ and Adera Debella $\mathbb{C}^{4}$ \\ ${ }^{1}$ Jugol General Hospital, Harari Reginal State, Harar, Ethiopia \\ ${ }^{2}$ Department of Nursing, College of Health and Medical Sciences, Madda Walabu University, Bale-Robe, Ethiopia \\ ${ }^{3}$ School of Public Health, College of Health and Medical Sciences, Haramaya University, Harar, Ethiopia \\ ${ }^{4}$ School of Nursing and Midwifery, College of Health and Medical Sciences, Haramaya University, Harar, Ethiopia \\ ${ }^{5}$ School of Medicine, College of Health and Medical Sciences, Haramaya University, Harar, Ethiopia \\ Correspondence should be addressed to Adera Debella; aksanadera62@gmail.com
}

Received 4 November 2021; Accepted 30 December 2021; Published 12 January 2022

Academic Editor: Joseph I. Ikechebelu

Copyright (C) 2022 Endalkachew Atnafu et al. This is an open access article distributed under the Creative Commons Attribution License, which permits unrestricted use, distribution, and reproduction in any medium, provided the original work is properly cited.

\begin{abstract}
Background. Annually, around 121 million unintended pregnancies occur in the world and more than 73 million encountered abortion. Ethiopia is also losing $19.6 \%$ of mothers due to unsafe abortion. Despite that postabortion contraceptive service is a climactic entry point for the prevention of unwanted pregnancy and associated deaths, the service magnitude and determinants immediately before discharge are not characterized well in Ethiopia. Hence, this study aimed to assess the magnitude of postabortion contraceptive utilization and associated factors among women receiving abortion care service before being discharged from health facilities in Harar, Eastern Ethiopia. Methods. A facility-based cross-sectional study was conducted among 390 women receiving abortion care services. At discharge, data about contraceptive acceptance and related maternal characteristics were collected. A binary logistic regression model was used to assess the association between independent and dependent variables (postabortion contraceptive utilization). Analysis was done with SPSS 22. Statistical significance was considered at $P<0.05$. Result. The overall prevalence of postabortion contraceptive utilization was $81.5 \%$ (95\% CI: 77.9, 85.4). Being unmarried (AOR, 0.05 ; 95\% CI $(0.02,0.16)$ ), having no history of previous abortion (AOR, $0.11 ; 95 \%$ CI $(0.04,0.34)$ ), being multigravida (AOR 8.1; 95\% CI $(2.20,13.40)$, lacking desire to have an additional child (AOR, 6.3; 95\% CI $(2.65,15.34)$, and history of family planning use (AOR, 17.20; 95\% CI $(6.5,38.60)$ ) were determinants of postabortion contraceptive utilization before being discharged from the health facilities. Conclusion. Postabortion contraceptive utilization in Harar health facilities still needs improvement as per the WHO and national recommendations. Therefore, the family planning provision strategies should be convincing and friendly, especially for unmarried mothers, and those who had no history of abortion should be counseled in friendly and systematically convincing schemes for enabling them to take the service before discharge from the health facility.
\end{abstract}

\section{Background}

Postabortion care is a series of medical and related interventions designed to manage the complication of spontaneous and induced abortions to address women-related health care needs $[1,2]$. It consists of essential elements such as emergency treatment of complications and provision of contraceptives, to prevent further mistimed or unplanned pregnancies that may result in repeated abortions [2-4]. Postabortion contraceptive use is the initiation of family planning methods immediately after an abortion $[1,2]$. The service plays an important role in reducing the unmet need for family planning, boosting contraceptive use prevalence, and averting unintended pregnancy and unsafe abortion [5]. 
Globally, an estimated 121 million unintended pregnancies occur each year, 61\% (73.3 million) of which end in abortion, corresponding to a global abortion rate of 39 abortions per 1000 women aged 15-49 years [6]. Unsafe abortion attribute to $4.7-13.2 \%$ of global maternal deaths [7], while an annual USD 553 million is estimated for treating major complications [8].

The majority of abortions occur in low- and middleincome countries, and sub-Saharan Africa has 27 abortion rates per 1000 women aged between 15 and 49 years [6]. In Ethiopia, an estimated number of 620,300 induced abortions were performed each year corresponding to a rate of 28 abortions per 1,000 women, 53\% of all occurring in health facilities, which provides an opportunity to offer contraceptive immediately after the provision of abortion service [9]. In Ethiopia, 22\% of currently married women have an unmet need for family planning, while complications of abortions attribute to $19.6 \%$ of maternal deaths in Ethiopia $[10,11]$.

The World Health Organization (WHO) recommends a six-month interpregnancy interval following induced or spontaneous abortion to ensure better maternal health [12]. Linking abortion care with family planning services reduces the unmet need and subsequent unintended pregnancies [4]. Studies conducted in Ethiopia showed that the prevalence of postabortion family planning utilization is disproportionate across different parts of the county ranging from $45.8 \%$ to 91\% [13-17].

Ethiopia has launched a new health sector transformation plan (HSTP) that constitutes improving settings for providing postabortion family planning services as a part of the strategy to reduce maternal morbidity and mortality [18]. Identifying the utilization and determinants of postabortion contraceptives is imperative for the implementation of HSTP. However, there is a scarcity of evidence to intervene on postabortion contraception and its determinants. So, this study was done to provide information on the magnitude and determinants of postabortion contraceptive use.

\section{Materials and Methods}

2.1. Study Design, Setting, and Period. This facility-based cross-sectional study was conducted from February 10 to March 30, 2018, in the health facilities of Harar Town which is located $526 \mathrm{~km}$ east of the capital city Addis Ababa. Both public and NGO health facilities that provide abortion services were included, 2 hospitals, 2 health centers, and 2 nongovernmental clinics. Harari region has a projected total population of 246,000 (124,000 males and 122,000 females) [19].

2.2. Study Participants and Eligibility Criteria. All women aged 15-49 years who came to health institutions in Harar Town for abortion care were the source population, while child-bearing women (15-49 years) who came to health facilities for abortion services were the study population. All women aged 15-49 years who had abortions in a health facility during the data collection period were included, but women who had threatened abortions and women who were unable to respond to the interview were excluded.

2.3. Sample Size Sampling Technique. The single-population proportion formula was used to determine the sample size for this study, using data on the proportion of postabortion family planning utilization done at Bahir Dar Town health facilities, Amhara regional state, which was 59.2\% [20], and considering 5\% nonresponse rate, we included 390 participants. Six health facilities were selected from Harar, and proportional allocation was done to recruit the required sample. The sample was taken consecutively until the desired sample size was achieved.

2.4. Data Collection Method and Quality Control. A standardized, structured, and interviewer-administered questionnaire was used to collect data on sociodemographic characteristics of the participants and other determinants of postabortion contraceptive use after reviewing relevant literature studies. The wording and sequence of questions were designed in a way that the sequence of ideas from general to specific and from easy to difficult questions was maintained. Data were collected during all working hours on clients immediately leaving the procedure room at the selected health facilities. Data collectors recruited study participants based on the inclusion and exclusion criteria. The data collectors explained the purpose of the study briefly and tried to get written and signed consent and proceed smoothly. The questionnaire was initially prepared in English and translated to the local languages (Afaan Oromo and Amharic languages). It was then translated back to English by language experts to check for its consistency. Training on the data collection tool and the procedures was provided to the data collectors and field supervisors. The questionnaire was pretested among 20 individuals who came to receive the service in similar settings before the actual study. Regular supervision was done by experienced field research supervisors and the investigators. The collected data were checked for completeness, cleaned, coded and entered into EPI DATA version 3.1. Then, the data were exported to SPSS version 22 for analysis.

2.5. Study Variables and Measurements. The outcome variable of this study was postabortion utilization of contraceptives (yes vs no) before being discharged from the health facilities. The independent variables included sociodemographic characteristics, obstetrics history, contraceptive, and health care-related characteristics.

2.5.1. Postabortion Contraceptive Utilization. This is the immediate start of contraception after completed surgical or medical abortion. It could be either health care provider administered or home-taken contraceptives [1, 4]. Either way of the initiations were considered postabortion contraceptive utilization. 
2.5.2. Postabortion Care $(P A C)$. This includes a package of services provided to a woman who have had an incomplete abortion after a spontaneous or induced abortion $[1,4]$.

2.5.3. Unsafe Abortion. This is a procedure for termination of pregnancy that is performed by an individual without the necessary skills or in an environment that does not conform to minimal medical standards, or both $[1,4]$.

2.6. Data Processing and Analysis. Descriptive statistics such as frequency, percentage, and mean with standard deviation were obtained for categorical variables. The outcome variable was recorded into binary as a contraceptive (yes$=$ contraceptive user and no=contraceptive nonuser). A binary logistic regression model was used to assess the association between the independent variables and postabortion contraceptive utilization status before being discharged. The model was fitted using Hosmer-Lemeshow and Omnibus tests. All variables that had a $P<0.25$ in the bivariable analysis were included in the final multivariable analysis to identify the adjusted determinants factors of postabortion contraceptive utilization. The association between the outcome and independent variables was reported using odds ratio (OR) along with the 95\% confidence interval. The statistical significance level was declared at a $P$ value of less than $<0.05$.

\section{Results}

3.1. Sociodemographic Characteristics of the Study Participants. A total of 390 abortion clients participated in this study yielding a response rate of $100 \%$. The mean $( \pm S D)$ age of the study participants was $24.4( \pm 5.6)$ years. About one-third, 133 (34.1\%), of the participants were in the age group of 20-24 years. Two hundred fifty-five (65.4\%), 217 (55.6\%), and 206 (52.8\%) women were Muslims, Oromo ethnic group, and married, respectively. About 161 (41.3\%) participants were housewives and had no formal education (Table 1).

3.2. Obstetrics, Contraceptive, and Health Care-Related Characteristics. Of the 390 respondents, 247 (63.3\%) were multigravida and $157(40.3 \%)$ women had the desire to give birth, of which $91 / 157$ (58.0\%) of them planned to give birth after thirty-six months. The majority, 372 (95.4\%), of pregnancies were unplanned. More than half, 210 (53.8\%), of women had a history of contraceptive use, among which 98 $(46.7 \%)$ of them were reported to use pills. One hundred fifty (38.4\%) participants were using family planning before the current abortion. About 184 (47.2\%) were safe abortion, and majority of termination, $292(75.1 \%)$, was undertaken in the first trimester, among which 359 (92.1\%) reported of using a combination of both medical abortion and manual vacuum aspiration. Among 390 study participants, 110 (28.2\%) had a history of previous abortion, of which 18 (16.4\%) had more than two abortions. Two hundred seventy-three (70.0\%) and 117 (30.0) used public health facilities and NGOs for current pregnancy termination, respectively, of which the majority, $355(91.0 \%)$, received postabortion family planning counseling. Nearly half, 194 (49.7\%), of the participants traveled ten to twenty kilometers to access health services and 270 $(69.2 \%)$ spend more than 30 minutes to get the services (Table 2).

3.3. Postabortion Contraceptive Acceptance and Determinants. In this study, the magnitude of postabortion contraceptive acceptance was $81.5 \%$ (95\% CI: 77.9, 85.4) (Figure 1). The multivariable logistic regression model showed that marital status, number of pregnancies, intention to have an additional child, history of contraceptive use, and history of abortion were factors significantly associated with postabortion contraceptive acceptance rate. Unmarried women were $95 \%$ less likely to use postabortion contraceptive (AOR: 0.05; 95\% CI: 0.017, 0.16).

Study participants who had no history of abortion were $89 \%$ less likely to use postabortion contraceptives compared to those who had no previous abortion history (AOR: 0.11; 95\% CI: 0.03, 0.34).

Odds of accepting contraceptive was 8 times more likely higher among multigravid mothers than among primigravid mothers (AOR: 8.1; 95\% CI: 2.2, 13.4).

Women who had a history of ever using family planning accepted contraceptives 17 times higher than their counterparts (AOR: 17.2; 95\% CI: 6.15, 38.6)

Odds of accepting contraceptive was 6 times higher among mothers who had no desire of having more children than among mothers who desired to have more children (AOR: 6.3 ; 95\% CI: 2.65, 15.3) who were more likely to use postabortion contraception as compared to their counterparts (Table 3).

\section{Discussion}

This cross-sectional study assessed postabortion contraceptive utilization and its associated factors among women receiving abortion care in health facilities of eastern Ethiopia. Accordingly, the proportion of use of family planning was $81.5 \%$.

In this study, $81.5 \%$ of postabortion contraceptive utilization among women receiving the care is in harmony with findings from similar studies in Ethiopia [21, 22], and other countries such as Mexico [23] and Nepal [24]. However, it is higher than reports from Pakistan [25] and other Ethiopian studies in Addis Ababa [26], Bahirdar [17], Gurage zone [27]. On the contrary, the current magnitude is lower than in similar previous studies done in Ethiopia and other countries $[14,28,29]$. These differences might be due to variations in the socioeconomic characteristics, the proportion of married women, study settings and periods, sample size, counseling, and availability of all contraceptive methods, misconceptions on family planning method of participants, and social norms.

This study pointed out that unmarried women were $95 \%$ less likely to utilize postabortion contraceptives than their counterparts. This is supported by studies conducted in a 
TABle 1: Socioeconomic and demographic characteristics of study participants in Harar Town health facility, Eastern Ethiopia $(N=390)$.

\begin{tabular}{|c|c|c|c|}
\hline Variables & Category & Frequency $(n)$ & Percent \\
\hline \multirow{5}{*}{ Age in years } & $\leq 19$ & 69 & 17.7 \\
\hline & $20-24$ & 133 & 34.1 \\
\hline & $25-29$ & 105 & 26.9 \\
\hline & $30-34$ & 51 & 13.1 \\
\hline & $\geq 35$ & 32 & 8.2 \\
\hline \multirow{2}{*}{ Place of residence } & Urban & 228 & 58.5 \\
\hline & Rural & 162 & 41.5 \\
\hline \multirow{3}{*}{ Marital status } & Married & 206 & 52.8 \\
\hline & Unmarried & 169 & 43.0 \\
\hline & Others* & 15 & 4.2 \\
\hline \multirow{4}{*}{ Educational status of women } & No formal education & 161 & 41.3 \\
\hline & Primary education & 100 & 25.6 \\
\hline & Secondary education & 100 & 25.6 \\
\hline & Higher education & 29 & 7.5 \\
\hline \multirow{3}{*}{ Religion } & Muslims & 255 & 65.4 \\
\hline & Orthodox & 131 & 33.6 \\
\hline & Protestant & 4 & 1.0 \\
\hline \multirow{5}{*}{ Ethnicity } & Oromo & 217 & 55.6 \\
\hline & Amhara & 91 & 23.3 \\
\hline & Harari & 45 & 11.5 \\
\hline & Gurage & 26 & 6.7 \\
\hline & Others** & 11 & 2.8 \\
\hline \multirow{4}{*}{ Educational status of husband } & No formal education & 64 & 16.4 \\
\hline & Primary education & 81 & 20.4 \\
\hline & Secondary education & 150 & 38.5 \\
\hline & Higher education & 95 & 24.4 \\
\hline \multirow{5}{*}{ Occupation of women } & Employed & 49 & 12.6 \\
\hline & Housewife & 161 & 41.3 \\
\hline & Farmer & 38 & 9.7 \\
\hline & Student & 12.4 & 31.8 \\
\hline & Others ${ }^{* * *}$ & 18 & 4.6 \\
\hline
\end{tabular}

${ }^{*}$ Divorced and widowed; ** Tigray and Somali; ${ }^{* * *}$ unemployed/job seeking.

different part of Ethiopia [14, 30-33]. The possible reason could be that married women would live together with their husbands so that they might be prone to more sexual exposure.

In this study, women who had a previous history of abortion were $89 \%$ more likely to utilize postabortion contraceptives compared to their counterparts. This is consistent with other studies done in East Africa and other parts of the country $[22,30,34]$. The possible explanation could be that the previous exposure to abortion might sensitize and influence the awareness of women towards postabortion contraceptive utilization. In addition, another reason could be the need to avoid being subjected to the treatment of abortion.

Women who had a previous history of contraceptive usage were 7 times more likely to utilize contraceptives as compared to their counterparts. Similarly, the study conducted in Pakistan [25] and other Ethiopian studies $[14,21,22,30,33]$ showed that the previous history of contraceptive usage was found to be significantly associated with postabortion contraceptive utilization. The possible explanation could be that the previous exposure to family planning services might influence the awareness of women towards postabortion contraceptive utilization.
In this finding, those partners who had an intention to have an additional child were 6.3 times less likely to utilize postabortion contraceptives than their counterparts. This is consistent with the study done in Tanzania and Ethiopia $[15,26,34]$. This might be due to the fact that those who intended to have an additional child consider to delay family planning until when the need arises or early planning for an additional (any) child.

Multigravida women were 8 times more likely to utilize postabortion contraceptives than primigravida. This finding was supported by the studies conducted in East Africa and other parts of Ethiopia $[30,33]$. This is due to the fact that women who had conceived frequently would choose to space birth compared to primigravida which might be related to socioeconomic or other related issues.

The strength of this study is the collection of data from clients immediately leaving the procedure room that enables them to clearly remember and express what they experienced which in turn minimizes recall bias. But, the study was a cross-sectional study and could not establish cause and effect relationship between postabortion contraceptives and the associated factors. 
TABLE 2: Obstetrics, contraceptive, and health care-related characteristics of study participants in the health facilities of Harar Town, Eastern Ethiopia $(N=390)$.

\begin{tabular}{|c|c|c|c|}
\hline Variables & Category & Frequency & Percent \\
\hline \multirow{2}{*}{ Gravidity } & Primigravida & 143 & 36.7 \\
\hline & Multigravida & 247 & 63.3 \\
\hline \multirow{2}{*}{ Need to have additional child } & Yes & 157 & 40.3 \\
\hline & No & 233 & 59.7 \\
\hline \multirow{3}{*}{ Planned to give additional child } & $<12$ & 30 & 19.1 \\
\hline & $12-36$ & 36 & 22.9 \\
\hline & $\geq 36$ & 91 & $58 \%$ \\
\hline \multirow{2}{*}{ Pregnancy type } & Planned & 18 & 4.6 \\
\hline & Unplanned & 372 & 95.4 \\
\hline \multirow{2}{*}{ History of modern family planning } & Yes & 210 & 53.8 \\
\hline & No & 180 & 46.2 \\
\hline \multirow{4}{*}{ Type of modern family planning $(n=210)$} & Pills & 98 & 46.7 \\
\hline & Injectables & 48 & 22.9 \\
\hline & Implanon & 50 & 23.8 \\
\hline & IUCD & 14 & 6.7 \\
\hline \multirow{2}{*}{ Information on family planning } & Yes & 204 & 52.3 \\
\hline & No & 186 & 47.7 \\
\hline \multirow{3}{*}{ Source of information } & Mass media & 77 & 37.7 \\
\hline & Health facilities & 101 & 49.5 \\
\hline & Others* & 26 & 12.8 \\
\hline \multirow{2}{*}{ History of family planning usage before the current abortion } & Yes & 150 & 38.4 \\
\hline & No & 240 & 61.6 \\
\hline \multirow{3}{*}{ Condition of abortion occurrence } & Forgetfulness & 70 & 46.4 \\
\hline & Discontinue due to side effects & 67 & 45 \\
\hline & Others** & 13 & 8.6 \\
\hline \multirow{2}{*}{ Purpose of abortion service visit } & Safe abortion care & 184 & 47.2 \\
\hline & Medical abortion care & 206 & 52.8 \\
\hline \multirow{2}{*}{ Trimester } & First trimesters & 292 & 75.1 \\
\hline & Second trimesters & 98 & 24.9 \\
\hline \multirow{2}{*}{ History of previous abortion } & Yes & 110 & 28.2 \\
\hline & No & 280 & 71.8 \\
\hline \multirow{2}{*}{ Number of previous abortions } & $\leq 2$ & 92 & 83.6 \\
\hline & $>2$ & 18 & 16.4 \\
\hline \multirow{2}{*}{ Place of current abortion terminated } & Public health facilities & 273 & 70.0 \\
\hline & NGOs & 117 & 30.0 \\
\hline \multirow{3}{*}{ Method of termination } & Medication abortion & 18 & 4.6 \\
\hline & Manual vacuum aspiration & 13 & 3.3 \\
\hline & Combination & 359 & 92.1 \\
\hline \multirow{2}{*}{ Receiving PAFP counseling } & Yes & 355 & 91.0 \\
\hline & No & 35 & 9.0 \\
\hline \multirow{3}{*}{ Distance from facilities } & $\leq 10 \mathrm{~km}$ & 129 & 17.2 \\
\hline & $10-20 \mathrm{~km}$ & 194 & 49.7 \\
\hline & $\geq 20 \mathrm{~km}$ & 67 & 33.1 \\
\hline \multirow{2}{*}{ Duration of stay for PAFP utilization } & $\leq 30$ minutes & 120 & 30.8 \\
\hline & $>30$ minutes & 270 & 69.2 \\
\hline \multirow{3}{*}{ Condition of health facilities } & Very good & 147 & 37.7 \\
\hline & Good & 172 & 44.1 \\
\hline & Satisfied & 71 & 18.2 \\
\hline \multirow{2}{*}{ Presence of latrine in the facilities } & Yes & 387 & 99.2 \\
\hline & No & 3 & 0.8 \\
\hline
\end{tabular}

${ }^{*}$ Peer, neighbors, and seminar; ${ }^{* *}$ being a student. 


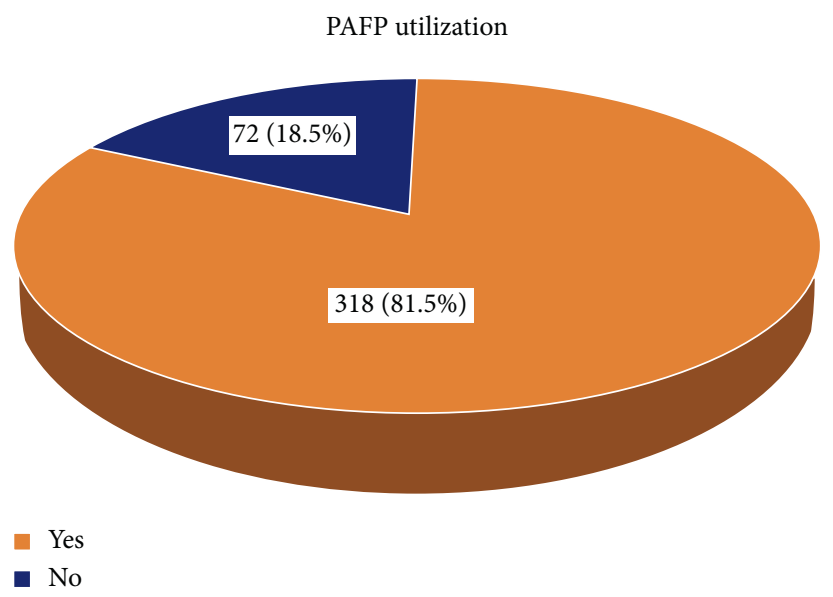

Figure 1: Magnitude of postabortion contraceptive utilization among women attending health facilities in Harar Town.

TABLE 3: Factors associated with postabortion contraceptive utilization among women receiving abortion service in health facilities of Harar Town, Eastern Ethiopia.

\begin{tabular}{|c|c|c|c|c|c|}
\hline \multirow[b]{2}{*}{ Variables } & \multirow[b]{2}{*}{ Category } & \multicolumn{2}{|c|}{ PAFP utilization } & \multirow[b]{2}{*}{ COR $(95 \%$ CI $)$} & \multirow[b]{2}{*}{ AOR $(95 \% \mathrm{CI})$} \\
\hline & & $\begin{array}{c}\text { Yes } \\
n(\%)\end{array}$ & $\begin{array}{c}\text { No } \\
n(\%)\end{array}$ & & \\
\hline \multirow{5}{*}{ Age } & $\leq 19$ & $56(81.2)$ & $13(18.8)$ & $1.4(0.52,3.91)$ & $0.50(0.16,1.56)$ \\
\hline & $20-24$ & $117(88.0)$ & $16(12.0)$ & $2.4(0.93,6.3)$ & $1.12(0.28,4.40)$ \\
\hline & $25-29$ & $83(79.0)$ & $22(21.0)$ & $1.2(0.49,3.6)$ & $1.13(0.24,5.6)$ \\
\hline & $30-34$ & $38(74.5)$ & $13(25.5)$ & $0.97(0.35,2.69)$ & $1.5(0.27,8.18)$ \\
\hline & $\geq 35$ & $24(75.0)$ & $8(25.0)$ & 1 & 1 \\
\hline \multirow{2}{*}{ Place of residence } & Urban & $227(90.8)$ & $23(9.2)$ & 1 & 1 \\
\hline & Rural & $91(65.0)$ & $49(35.0)$ & $0.57(0.34,0.95)$ & $1.72(0.82,3.65)$ \\
\hline \multirow{3}{*}{ Marital status } & Married & $179(86.9)$ & $27(13.1)$ & 1 & 1 \\
\hline & Unmarried & $127(75.1)$ & $42(24.9)$ & $0.45(0.26,0.77)$ & $0.05(0.017,0.16)^{* *}$ \\
\hline & Other ${ }^{*}$ & $4(26.6)$ & $11(20.0)$ & $0.6(0.16,2.27)$ & $3.2(0.56,18.6)$ \\
\hline \multirow{4}{*}{ Maternal educational status } & No formal & $131(81.4 \%)$ & $30(18.6 \%)$ & 1 & 1 \\
\hline & Primary & $82(82.0 \%)$ & $18(18.0 \%)$ & $0.95(0.50 .1 .82)$ & $1.04(0.42,2.55)$ \\
\hline & Secondary & $78(78 \%)$ & $22(22 \%)$ & $1.23(0.66,2.28)$ & $1.90(0.74,4.879)$ \\
\hline & Higher education & $27(93 \%)$ & $2(6.9 \%)$ & $0.32(0.73,1.43)$ & $1.02(0.14,7.07)$ \\
\hline \multirow{2}{*}{ Number of pregnancies } & Multigravida & $188(76.1)$ & $59(23.9)$ & $0.3(0.16,0.60)$ & $8.1(2.2,13.4)^{* *}$ \\
\hline & Primigravida & $130(91.0)$ & $13(9.0)$ & 1 & 1 \\
\hline \multirow{2}{*}{ History of abortion } & Yes & $103(03.6 \%)$ & $7(6.4 \%)$ & 1 & 1 \\
\hline & No & $215(76.8 \%)$ & $65(23.2 \%)$ & $0.22(0.1,0.5)$ & $0.11(0.03,0.34)^{* *}$ \\
\hline \multirow{2}{*}{ Need of additional child } & Yes & $106(67.5 \%)$ & $51(32.5 \%)$ & 1 & 1 \\
\hline & No & $212(91.0 \%)$ & $21(9.0 \%)$ & $0.20(0.11,0.36)$ & $6.3(2.65,15.3)^{* *}$ \\
\hline \multirow{2}{*}{ History of FP use } & Yes & $202(96.2)$ & $8(3.8)$ & $13.9(6.4,30.0)$ & $17.2(6.15,38.6)$ \\
\hline & No & $116(64.4)$ & $64(35.6)$ & 1 & 1 \\
\hline \multirow{2}{*}{ Information on FP } & Yes & $184(90.2 \%)$ & $20(9.8 \%)$ & $3.5(2.0 ., 6.2)$ & $0.77(0.33,1.81)$ \\
\hline & No & $134(72.0 \%)$ & $52(28.0 \%)$ & 1 & \\
\hline
\end{tabular}

${ }^{*}$ Divorced and widowed; ${ }^{* *} P$ value $<0.05$.

\section{Conclusions and Remarks}

Generally, this study pointed out that postabortion contraceptive utilization in Harar health facilities is good but could be improved as per the WHO and national recommendations. Marital status, history of abortion, history of family planning, intention to have an additional child, and the number of pregnancies determined postabortion contraceptive utilization. The Ministry of Health, the regional health bureau, and health care providers at health facilities have an opportunity to work on the enhancement of family planning exposure and prevention of primary abortion especially on unmarried women of the reproductive age group. There should also be an emphasized client-provider communication on the need for contraception in the first six postabortion periods even if they want more (any) child. 


\author{
Abbreviations \\ AOR: $\quad$ Adjusted odds ratio \\ FP: $\quad$ Family planning \\ HSTP: Health sector transformation plan \\ IHRERC: Institutional health research ethics review \\ committee \\ NGO: Nongovernmental organizations \\ PAFP: Postabortion family planning \\ IUCD: Intrauterine contraceptive device \\ WHO: World Health Organization.
}

\section{Data Availability}

The data used to support the findings of this study are available from the corresponding author upon request.

\section{Ethical Approval}

This study was conducted in accordance with the Helsinki Declaration of conducting research on humans. Ethical approval was obtained from Institutional Health Research Ethics Review Committee (IHRERC) of Haramaya University, College of Health and Medical Sciences. Support letters from College of Health and Medical Sciences were submitted to the selected hospitals where the study was conducted.

\section{Consent}

After getting all permission letters from the responsible body, informed voluntary written consent was signed by study participants. Confidentiality was maintained by using codes instead of the participant's name. Participants were also informed that they have full right to refuse participation or withdraw any time from the research.

\section{Disclosure}

The funding body had no role in the collection, analysis and interpretation of the data, and the write up and publication of this article.

\section{Conflicts of Interest}

The authors declare that they have no conflicts of interest.

\section{Authors' Contributions}

All authors made significant contributions to conception and design, acquisition of data, and analysis and interpretation; took part in drafting and revising the paper critically for important intellectual contents; gave final approval of the version to be published; and agreed to be accountable for all aspect of the work.

\section{Acknowledgments}

Haramaya University provided the financial supports for this study. The authors are thankful to Haramaya University, College of Health and Medical Science, heads and staff of the selected hospitals, study participants, data collectors, and field supervisors.

\section{References}

[1] World Health Organization WHO, Counselling for Maternal and Newborn Health Care: A Handbook for Building Skills, World Health Organization, Geneva, Switzerland, 2013.

[2] World Health Organization WHO, Clinical Practice Handbook for Safe Abortion, World Health Organization, Geneva, Switzerland, 2014.

[3] N. Abdel-Tawab and S. Saher, "Challenges and opportunities in providing postabortion family planning services," in Proceedings of the XXVI IUSSP International Population Conference, Marrakech, Morocco, September 2009.

[4] A. Ceylan, M. Ertem, G. Saka, and N. Akdeniz, "Post abortion family planning counseling as a tool to increase contraception use," BMC Public Health, vol. 9, no. 1, 2009.

[5] D. Huber, C. Curtis, L. Irani, S. Pappa, and L. Arrington, "Postabortion care: 20 years of strong evidence on emergency treatment, family planning, and other programming components," Global Health: Science and Practice, vol. 4, no. 3, pp. 481-494, 2016.

[6] J. Bearak, A. Popinchalk, B. Ganatra et al., "Unintended pregnancy and abortion by income, region, and the legal status of abortion: estimates from a comprehensive model for 1990-2019," The Lancet Global Health, vol. 8, no. 9, pp. e1152-e1161, 2020.

[7] L. Say, D. Chou, A. Gemmill et al., "Global causes of maternal death: a WHO systematic analysis," The Lancet Global health, vol. 2, no. 6, pp. e323-e333, 2014.

[8] M. Vlassoff, "Economic impact of unsafe abortion-related morbidity and mortality: evidence and estimation challenges," Report, University of Sussex, Brighton, UK, 2008.

[9] A. M. Moore, Y. Gebrehiwot, T. Fetters et al., "The estimated incidence of induced abortion in Ethiopia, 2014: changes in the provision of services since 2008," International Perspectives on Sexual and Reproductive Health, vol. 42, no. 3, pp. 111-120, 2016.

[10] Central Stastics Agency CSA, Ethiopian Demographic and Health Survey 2016, Central Stastics Agency, Addis Ababa, Ethiopia, 2017.

[11] G. A. Tessema, C. O. Laurence, Y. A. Melaku et al., "Trends and causes of maternal mortality in Ethiopia during 1990-2013: findings from the global burden of diseases study 2013," BMC Public Health, vol. 17, no. 1, 2017.

[12] Wold Health Organization WHO, Report of a WHO Technical Consultation on Birth Spacing, World Health Organization, Geneva, Switzerland, 2007.

[13] E. Abate, Y. R. Smith, W. Kindie, A. Girma, and Y. Girma, "Prevalence and determinants of post-abortion family planning utilization in a tertiary hospital of Northwest Ethiopia: a cross sectional study," Contraception and Reproductive Medicine, vol. 5, no. 1, p. 39, 2020.

[14] M. Asrat, D. Bekele, and S. D. Rominski, "Post-abortion contraceptive acceptance and choice among women receiving abortion care at saint paul's hospital, Addis Ababa, Ethiopia: a cross-sectional study," The Lancet Global Health, vol. 6, p. S37, 2018.

[15] C. Baynes, E. Yegon, G. Lusiola, J. Achola, and R. Kahando, "Post-abortion fertility desires, contraceptive uptake and unmet need for family planning: voices of post-abortion care clients in Tanzania," Journal of Biosocial Science, vol. 53, no. 6, pp. 908-923, 2020. 
[16] A. Muche, B. Bewket, E. Ayalew, and E. Demeke, "Utilization of post abortal contraceptive use and associated factors among women who came for abortion service at Debre Berhan hospital, Debre Berhan, Ethiopia March 2019: institution based cross sectional study," Clinical Journal of Obstetrics and Gynecology, vol. 2, no. 1, pp. 025-033, 2019.

[17] A. Muchie, F. A. Getahun, Y. A. Bekele, T. Samual, and T. Shibabaw, "Magnitudes of post-abortion family planning utilization and associated factors among women who seek abortion service in Bahir Dar town health facilities, Northwest Ethiopia, facility-based cross-sectional study," PLoS One, vol. 16, Article ID e0244808, 2021.

[18] Ministry of Health of Ethiopia, Ethiopia-Health-SystemTransformation-Plan(HSTP), Ministry of Health of Ethiopia, Addis Ababa, Ethiopia, 2015.

[19] Central Statistical Agency, 2007 Population and Housing Census of Ethiopia, Central Statistical Agency, Addis Ababa, Ethiopia, 2012.

[20] L. Kokeb, E. Admassu, H. Kassa, and T. Seyoum, "Utilization of post abortion contraceptive and associated factors among women who came for abortion service: a hospital based cross sectional study," Journal of Family Medicine and Disease Prevention, vol. 1, p. 022, 2015.

[21] A. M. Abebe, M. Wudu Kassaw, and N. Estifanos Shewangashaw, "Postabortion contraception acceptance and associated factors in dessie health center and marie stopes international clinics, South Wollo Northeast, Amhara region, 2017," International Journal of Reproductive Medicine, vol. 2019, Article ID 1327351, 10 pages, 2019.

[22] A. Mekuria, H. Gutema, H. Wondiye, and M. Abera, "Postabortion contraceptive use in Bahir Dar, Ethiopia: a cross sectional study," Contraception and Reproductive Medicine, vol. 4, no. 1, p. 19, 2019.

[23] D. Becker, C. Díaz Olavarrieta, S. G. Garcia, and C. C. Harper, "Women's reports on postabortion family-planning services provided by the public-sector legal abortion program in Mexico city," International Journal of Gynecology \& Obstetrics, vol. 121, no. 2, pp. 149-153, 2013.

[24] V. Khanal, C. Joshi, D. Neupane, and R. Karkee, "Practices and perceptions on contraception acceptance among clients availing safe abortion services in Nepal," Kathmandu University Medical Journal, vol. 9, no. 3, pp. 179-184, 2011.

[25] S. K. Azmat, W. Hameed, M. Ishaque, G. Mustafa, and A. Ahmed, "Post-abortion care family planning use in Pakistan," Pakistan Journal of Public Health, vol. 2, p. 10, 2012.

[26] N. Prata, S. Bell, M. Holston, C. Gerdts, and Y. Melkamu, "Factors associated with choice of post-abortion contraception in Addis Ababa, Ethiopia," African Journal of Reproductive Health, vol. 15, pp. 51-57, 2011.

[27] G. Tesfaye and L. Oljira, "Post abortion care quality status in health facilities of Guraghe zone, Ethiopia," Reproductive Health, vol. 10, no. 1, p. 35, 2013.

[28] K. Chukwumalu, M. C. Gallagher, S. Baunach, and A. Cannon, "Uptake of postabortion care services and acceptance of postabortion contraception in Puntland, Somalia," Reproductive Health Matters, vol. 25, no. 51, pp. 48-57, 2017.

[29] A. L. C. Ferreira, A. I. Souza, R. A. Lima, and C. Braga, "Choices on contraceptive methods in post-abortion family planning clinic in the northeast Brazil," Reproductive Health, vol. 7, no. 1, p. 5, 2010.

[30] A. D. Bizuneh and G. G. Azeze, "Post-abortion family planning use, method preference, and its determinant factors in Eastern Africa: a systematic review and meta-analysis," Systematic Reviews, vol. 10, no. 1, p. 172, 2021.

[31] D. Seyoum, A. Gebeyehu, and Z. Gizaw, "Assessment of post abortion contraceptive intention and associated factors among abortion clients in Gondar town, North West Ethiopia, 2013," Universal Journal of Public Health, vol. 2, no. 8, pp. 215-225, 2014.

[32] E. Erko, M. Abera, and A. Bitiya, "Safe abortion care, utilization of post abortion contraception and associated factors," Jimma Ethiopia, vol. 4, pp. 5-9, 2016.

[33] Y. Moges, T. Hailu, B. Dimtsu, Z. Yohannes, and B. Kelkay, "Factors associated with uptake of post-abortion family planning in Shire town, Tigray, Ethiopia," BMC Research Notes, vol. 11, no. 1, p. 928, 2018.

[34] N. Prata, M. Holston, A. Fraser, and Y. Melkamu, "Contraceptive use among women seeking repeat abortion in Addis Ababa, Ethiopia," African Journal of Reproductive Health, vol. 17, pp. 56-65, 2013. 